\title{
Blood Magnesium Level and Selected Oxidative Stress Indices in Lead-Exposed Workers
}

\author{
Magdalena Wyparło-Wszelaki ${ }^{1}$ (D) - Marta Wąsik ${ }^{1}$ (D) - Anna Machoń-Grecka ${ }^{1}$ (D) - Aleksandra Kasperczyk ${ }^{1}$ (D)

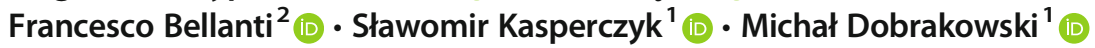

Received: 3 February 2020 / Accepted: 24 April 2020 / Published online: 6 May 2020

(C) The Author(s) 2020

\begin{abstract}
Occupational exposure to lead is one of the important hazards to human global population. Lead interferes with divalent cations, such as calcium, magnesium, and iron. Magnesium is the fourth most common mineral in the human body and a cofactor in more than 325 enzymes. There are many disorders associated with magnesium deficiency. It has been postulated that hypomagnesemia promotes oxidative stress. Study population included 232 male employees of lead-zinc works and was divided into two subgroups based on the median of magnesium serum level: low magnesium level (L-Mg) group and high magnesium level (H-Mg) group. Magnesium level was significantly higher in the H-Mg group than in the L-Mg group due to the study design. The level of zinc protoporphyrin was significantly higher in the L-Mg group than in the $\mathrm{H}-\mathrm{Mg}$ group by $13 \%$, while the blood lead levels were similar in the examined groups. The serum level of MDA was significantly higher in the L-Mg group than in the H-Mg group by $12 \%$, while the serum levels of thiol groups, TAC, and bilirubin were significantly lower in that group by $6 \%, 3 \%$, and $27 \%$, respectively. Similarly, the erythrocyte SOD activity was lower in the L-Mg group than in the H-Mg group by $5 \%$. Low serum magnesium levels contribute to lead-induced oxidative stress, result in unfavorable modification of antioxidant system function, and promote lead-induced impairment of heme synthesis. Obtained results indicate that prevention of hypomagnesemia should be regarded as an important step in ensuring adequate prophylaxis of chronic lead poisoning.
\end{abstract}

Keywords Magnesium $\cdot$ Oxidative stress $\cdot$ Lead exposure

\section{Introduction}

Heavy metals have become a global health problem. One of them is lead that is toxic to humans and animals. Lead is widespread in the environment, including water, soil, and dust. Lead can be also present in manufactured products. Therefore, environmental and occupational exposure to lead is one of the important hazards to human global population [1]. Lead together with mercury and cadmium are classified as the most relevant toxic substances in general and are included

Anna Machoń-Grecka

machongrecka.a@gmail.com

1 Department of Biochemistry, Faculty of Medical Sciences in Zabrze, Medical University of Silesia, ul. Jordana 19, 41-808 Zabrze, Poland

2 Department of Medical and Surgical Sciences, University of Foggia, viale Pinto, 1, 71122 Foggia, Italy in the top 10 chemicals of major public health concern according to the World Health Organization (WHO) [2].

The gastrointestinal and respiratory tracts are the main routes of lead absorption. Lead affects all body systems. The most susceptible to lead toxic effects are erythropoiesis, kidney function, and the central nervous system function [2]. Lead affects adversely also the cardiovascular system and increases the incidence of hypertension, coronary artery disease, left ventricular hypertrophy, alterations in cardiac rhythm, and peripheral artery disease [3].

There are many possible mechanisms of lead toxicity. Thanks to a strong electron sharing property, lead forms covalent bonds with the sulfhydryl groups of proteins, making the enzymes most susceptible targets for lead, including antioxidant enzymes. Lead neutralizes also glutathione (GSH) that serves as the major thiol antioxidant. These interferences result in an imbalance between production and neutralization of reactive oxygen species (ROS) due to lead action [4]. Besides, lead has pro-inflammatory properties associated with 
its influence on the cytokine metabolism, the expression and activity of enzymes involved in the inflammation, and the levels of acute-phase proteins [5]. Lead also interferes with divalent cations, such as calcium, magnesium, and iron. By their substitution, lead can affect various fundamental biological processes [3].

Magnesium is the fourth most common mineral in the human body and a cofactor in more than 325 enzymes. There are many disorders associated with magnesium deficiency, such as hypertension, atherosclerosis, cardiac arrhythmias and infarct, dyslipidemia, insulin resistance, metabolic syndrome, osteoporosis, and neuropsychiatric disorders [6]. It has been postulated that hypomagnesemia promotes oxidative stress. First of all, decreased level of magnesium impairs function of respiratory chain and leads to mitochondrial dysfunction and increased ROS release. Secondly, hypomagnesemia results in increased levels of pro-inflammatory cytokines and neutrophils as well as macrophages activation. These cells act as a source of superoxide anions due to NADPH oxidase activity. Thirdly, decreased ratio of magnesium to calcium is supposed to increase levels of catecholamines and activate renin-angiotensin-aldosterone axis that also induces oxidative stress. Fourthly, magnesium is believed to protect cell membranes from oxidative damage. On the other hand, oxidative stress favors hypomagnesemia $[6,7]$.

In light of the above-mentioned information, it can be hypothesized that low magnesium levels may enhance lead toxicity in respect of oxidative stress and inflammatory response. In parallel, lead-induced oxidative stress may contribute to hypomagnesemia as a positive feedback mechanism. However, there is limited information in the available literature on relating lead and magnesium [8]. Therefore, we aimed to investigate associations among lead, magnesium, and oxidative stress parameters in chronically lead-exposed workers.

\section{Materials and Methods}

\section{Study Population}

Study protocol was approved by the Bioethics Committee of Medical University of Silesia (Permission No. KNW/022/ KB1/108/14).

Examined population included 232 male employees of lead-zinc works in Miasteczko Śląskie, Poland. During prophylactic medical examination, epidemiological data were collected, such as age, duration of employment in lead exposure, smoking habits, and medical history. Besides, body mass and height were measured to calculate body mass index (BMI). Lead exposure was estimated based on blood levels of lead and zinc protoporphyrin (ZPP). Inclusion criteria for the study were as follows: occupational exposure to lead and blood lead level exceeding $25 \mu \mathrm{g} / \mathrm{dl}$.
The study population was divided into two sub-groups based on the median of magnesium serum level $(0.862 \mathrm{mmol} / \mathrm{l})$ : low magnesium level group (L-Mg group, $n=116$ ) and high magnesium level group (H-Mg group, $n=$ 116). Serum magnesium level ranged $0.863-1.543 \mathrm{mmol} / 1$ in the $\mathrm{H}-\mathrm{Mg}$ group and $0.629-0.861 \mathrm{mmol} / \mathrm{l}$ in the $\mathrm{L}-\mathrm{Mg}$ group.

This work was supported by Medical University of Silesia (Grant No. KNW-2-08/N/8/N).

\section{Laboratory Procedures}

Blood samples from each subject were collected from the cubital vein using tubes (Vacuette; Greiner-Bio, Frickenhausen, Germany) coated with $\mathrm{K}_{3}$ EDTA to obtain whole blood, serum, and erythrocytes.

Assessments of the $\mathrm{PbB}$ were performed using graphite furnace atomic absorption spectrometry in an ICE 3400 (Thermo Fisher Scientific, Waltham, MA, USA). The results were expressed as $\mu \mathrm{g} / \mathrm{dl}$.

The blood concentration of zinc protoporphyrin (ZPP) was measured directly using Aviv Biomedical hematofluorometer model 206, using an excitation wavelength of $415 \mathrm{~nm}$ and an emission wavelength of $596 \mathrm{~nm}$. The results were expressed as $\mu \mathrm{g}$ ZPP per g of hemoglobin ( $\mu \mathrm{g} / \mathrm{g} \mathrm{Hb})$.

Assessments of the magnesium levels were performed using graphite furnace atomic absorption spectrometry in an ICE 3400 (Thermo Fisher Scientific, Waltham, MA, USA). The results were expressed as $\mathrm{mmol} / \mathrm{l}$.

The analyzer Sysmex K-4500 (GMI, MN, USA) was used to determine parameters of the blood morphology: white blood cell (WBC) count, red blood cell (RBC) count, hemoglobin (HGB) level, hematocrit (HCT), platelet (PLT) count.

Total antioxidant capacity (TAC) was measured in serum according to Erel [9]. Data were expressed as mmol/l. Total oxidant status (TOS) was measured in serum according to Erel [10]. Data were expressed as $\mu \mathrm{mol} / \mathrm{l}$. Oxidative stress index (OSI) was calculated as the percentage ratio of TOS to TAC.

The serum concentration of bilirubin was measured using PerkinElmer biochemical analyzer according to the manufacturer's instructions. Bilirubin concentration was expressed as $\mu \mathrm{mol} / 1$.

The method of Arab and Steghens [11] was used to measure the concentrations of lipid hydroperoxides (LPH) in serum. The results were shown in $\mu \mathrm{mol} / 1$.

The level of malondialdehyde (MDA), a product of lipid peroxidation, was measured fluorometrically as a 2thiobarbituric acid-reactive substance (TBARS) in serum according to Ohkawa, Ohishi, and Yagi [12] with modifications. Samples were mixed with $8.1 \%$ sodium dodecyl sulfate, $20 \%$ acetic acid, and $0.8 \%$ 2-thiobarbituric acid. After vortexing, samples were incubated for $1 \mathrm{~h}$ in $95^{\circ} \mathrm{C}$ and butanol-pyridine 15:1 (v/v) was added. The mixture was shaken for $10 \mathrm{~min}$ and then centrifuged. The butanol-pyridine layer was measured 
Table 1 Epidemiologic data and percentages of chronic diseases in low magnesium level group (L-Mg group) and high magnesium level group (H-Mg group).

\begin{tabular}{|c|c|c|c|c|c|}
\hline & \multirow{2}{*}{\multicolumn{2}{|c|}{$\frac{\text { L-Mg group }}{n=116}$}} & \multirow{2}{*}{\multicolumn{2}{|c|}{$\frac{\text { H-Mg group }}{n=116}$}} & \multirow[t]{3}{*}{$p$} \\
\hline & & & & & \\
\hline & Mean & SD & Mean & SD & \\
\hline Age (year) & 40.9 & 9.77 & 42.3 & 9.58 & 0.285 \\
\hline Employment duration (year) & 14.9 & 8.01 & 15.4 & 7.52 & 0.637 \\
\hline Height $(\mathrm{cm})$ & 176 & 5.92 & 176 & 6.76 & 0.988 \\
\hline Weight $(\mathrm{kg})$ & 86.3 & 12.9 & 86.1 & 13.0 & 0.905 \\
\hline Smoking habits (year) & 15.2 & 8.30 & 15.0 & 8.40 & 0.891 \\
\hline Diabetes & $2 \%$ & & $4 \%$ & & 0.353 \\
\hline Coronary artery disease & $2 \%$ & & $2 \%$ & & 0.933 \\
\hline Arterial hypertension & $15 \%$ & & $13 \%$ & & 0.702 \\
\hline
\end{tabular}

$p$ value- $t$ test, $p<0.05$

fluorometrically at 515-nm and 522-nm excitation (PerkinElmer, USA). TBARS values were expressed as malondialdehyde (MDA) equivalents. Tetraethoxypropane was used as the standard. Concentrations were given in $\mu \mathrm{mol} / \mathrm{l}$ (serum) and in $\mathrm{nmol} / \mathrm{g} \mathrm{Hb}$ (erythrocytes).

Concentration of lipofuscin (LPS) was measured according to the method of Tsuchida et al. [13]; results were shown in RU/l (relative unit, RU) and RU/g Hb (erythrocytes).

Protein sulfhydryl groups (PSH) concentration was determined as described by Koster, Biemond, and Swaak [14] using DTNB, which undergoes reduction by compounds containing sulfhydryl groups, yielding the yellow anion derivative, 5-thio-2-nitrobenzoate, which absorbs at a wavelength of $412 \mathrm{~nm}$ using an automated analyzer PerkinElmer. The results were shown in $\mu \mathrm{mol} / \mathrm{g}$ protein and $\mu \mathrm{mol} / \mathrm{l}$.

Ceruloplasmin (CER) concentration in serum was determined as described by Richterich [15]. The results were shown in $\mathrm{mg} / \mathrm{dl}$.

The method of Oyanagui [16] was used to measure the activity of SOD in serum and erythrocytes. Activities of superoxide dismutase (SOD) were expressed in NU/ml (serum) and $\mathrm{NU} / \mathrm{mg} \mathrm{Hb}$ (erythrocytes). Catalase (CAT) activity in erythrocytes was measured by the method of Johansson and
Håkan Borg [17] using an automated analyzer PerkinElmer. The activity of CAT was expressed as kIU/g Hb. The activity of glutathione reductase (GR) in erythrocytes was measured according to Richterich [15] using an automated analyzer PerkinElmer. The activity was expressed as $\mu$ moles of NADPH utilized per minute per $g$ hemoglobin in erythrocytes (IU/g Hb). The activity of glutathione S-transferase (GST) in erythrocytes was measured according to the kinetic method of Habig and Jakoby [18] using an automated analyzer PerkinElmer. The activity of GST was expressed as $\mu$ moles of thioether produced per minute per $\mathrm{g}$ hemoglobin in erythrocytes $(\mathrm{mIU} / \mathrm{g} \mathrm{Hb})$. Glutathione peroxidase (GPx) activity in erythrocytes was measured by the kinetic method of Paglia and Valentine [19]. The activity of GPx was expressed as micromoles of NADPH oxidized per minute per g hemoglobin in erythrocytes $(\mathrm{IU} / \mathrm{g} \mathrm{Hb})$.

\section{Statistical Analysis}

Statistical analysis was performed using Statistica 10.0 PL software. Results were reported as mean \pm standard deviation (SD) for normal distribution. Shapiro-Wilk's test was used to verify normality, and Levene's test was used to verify homogeneity of variances. Statistical comparisons were made using a $t$ test, a $t$ test with separate variance estimates, a MannWhitney $U$ test, or a chi-squared test. The Spearman nonparametric correlation was calculated. Additionally, regression analysis was performed. A $p$ value $<0.05$ was considered statistically significant.

\section{Results}

The mean values of age, employment duration, height, weight, BMI, and smoking habits did not differ between the examined groups (Table 1). The percentages of participants diagnosed with diabetes, arterial hypertension, and coronary artery disease were also not different in the examined groups (Table 1).

Magnesium level was significantly higher in the $\mathrm{H}-\mathrm{Mg}$ group than in the L-Mg group due to the study design. The level of ZPP was significantly higher in the L-Mg group than
Table 2 Magnesium level and lead exposure markers in low magnesium level group (L-Mg group) and high magnesium level group (H-Mg group). $\mathrm{PbB}$ blood lead level, $Z P P$ zinc protoporphyrin.

\begin{tabular}{|c|c|c|c|c|c|c|}
\hline & \multicolumn{2}{|c|}{ L-Mg group } & \multicolumn{2}{|c|}{ H-Mg group } & \multirow{2}{*}{$\begin{array}{l}\text { Relative } \\
\text { change \% }\end{array}$} & \multirow[t]{2}{*}{$p$} \\
\hline & Mean & $\mathrm{SD}$ & Mean & $\mathrm{SD}$ & & \\
\hline $\mathrm{Mg}(\mathrm{mmol} / \mathrm{l})$ & 0.78 & 0.06 & 0.97 & 0.15 & $24 \%$ & $<0.001$ \\
\hline $\mathrm{PbB}(\mu \mathrm{g} / \mathrm{dl})$ & 35.3 & 6.01 & 34.7 & 6.13 & $-2 \%$ & 0.394 \\
\hline $\mathrm{ZPP}(\mu \mathrm{g} / \mathrm{g} \mathrm{Hb})$ & 5.85 & 3.36 & 5.08 & 2.05 & $-13 \%$ & 0.036 \\
\hline
\end{tabular}

$p$ value- $t$ test, $p<0.05$ 
Table 3 Blood morphology parameters in low magnesium level group (L-Mg group) and high magnesium level group ( $\mathrm{H}-\mathrm{Mg}$ group). $W B C$ white blood cells, $R B C$ red blood cells, $H G B$ hemoglobin, HTC hematocrit, PLT platelets.

\begin{tabular}{lcccccccc}
\hline & \multicolumn{2}{c}{ L-Mg group } & & \multicolumn{2}{l}{ H-Mg group } & \multicolumn{2}{l}{$\begin{array}{l}\text { Relative } \\
\text { change } \%\end{array}$} & $p$ \\
\cline { 2 - 3 } & Mean & SD & & Mean & SD & & \\
\hline WBC (G/l) & 7.32 & 1.84 & & 7.04 & 2.10 & $-4 \%$ & 0.290 \\
RBC (T/l) & 4.85 & 0.38 & & 4.89 & 0.33 & $1 \%$ & 0.455 \\
HGB (g/dl) & 15.1 & 0.89 & 15.2 & 0.83 & $1 \%$ & 0.422 \\
HTC (\%) & 42.8 & 2.47 & 43.1 & 2.28 & $1 \%$ & 0.433 \\
PLT (G/l) & 238 & 50.6 & 226 & 53.5 & $-5 \%$ & 0.036 \\
\hline
\end{tabular}

$p$ value $-t$ test, $p<0.05$

in the $\mathrm{H}-\mathrm{Mg}$ group by $13 \%$, while the blood lead levels were similar in the examined groups (Table 2).

PLT count was significantly lower in the L-Mg group than in the $\mathrm{H}-\mathrm{Mg}$ group by $5 \%$, whereas the remaining measured parameters of blood morphology were not different between the examined groups (Table 3).

The serum level of MDA was significantly higher in the $\mathrm{L}-\mathrm{Mg}$ group than in the $\mathrm{H}-\mathrm{Mg}$ group by $12 \%$, while the serum levels of thiol groups, TAC, and bilirubin were significantly lower in that group by $6 \%, 3 \%$, and $27 \%$, respectively (Table 4). Similarly, the erythrocyte SOD activity was lower in the L-Mg group than in the $\mathrm{H}-\mathrm{Mg}$ group by $5 \%$ (Table 5).

The correlation analysis showed positive correlations between magnesium level and the levels of TAC $(R=0.13, p=$ $0.017)$, thiol groups $(R=0.21, p=0.001)$, and bilirubin $(R=$ $0.18, p=0.024)$ as well as the activity of $\operatorname{SOD}(R=0.13, p=$ $0.048)$. Negative correlations between magnesium level and the levels of ZPP $(R=-0.26, p=0.005)$, MDA $(R=-0.16$, $p=0.017)$, and PLT count $(R=-0.15, p=0.026)$ were also reported (Table 6).

The regression analysis (Table 7) showed that the levels/ activities of measured parameters in the following order: PSH ( $\beta=0.22)$, ZPP $(\beta=-0.19)$, MDA $(\beta=-0.17)$, and SOD $(\beta=0.17)$ are associated with the blood magnesium level.

\section{Discussion}

There are several epidemiological studies that link blood lead level with the levels of major and minor elements. Most of them was conducted on children. The results are not concordant. Li et al. [20] found a positive correlation between blood levels of lead and magnesium in 2457 children (57.21 \pm $35.00 \mu \mathrm{g} / \mathrm{l})$ aged from 6 to 14 years who were recruited in Nanning, China, while $\mathrm{Wu}$ et al. [21] reported a negative correlation between blood levels of lead and magnesium in 3181 children $(4.29 \pm 2.38 \mu \mathrm{g} / \mathrm{dl})$ aged from 0 to 14 years who were recruited in Bejing, China. Liu et al. [22] and Zhao et al. [23] found no association between blood levels of lead and magnesium in 1551 children $(41.16 \pm 16.10 \mu \mathrm{g} / \mathrm{l})$ aged 1 to 72 months recruited in Nanjing, China, and in 1110 children $(49.42 \pm 20.16)$, aged 0 to 6 years recruited in Jinan, China, respectively. Długaszek and Skrzeczanowski [24] showed a positive correlation between hair content of lead and magnesium in boys aged 11 to 15 years. Analogical correlations were found in cartilage and anterior cruciate ligament of the knee joints obtained from 22 women aged 52 to 83 years and 8 men aged 42 to 79 years [25]. In the present study, blood magnesium levels did not correlate with blood lead levels and in the majority of study participants were within the normal range. The discrepancies between above-mentioned results are probably due to many possible factors that may interfere with
Table 4 Oxidative stress markers in serum in low magnesium level group (L-Mg group) and high magnesium level group (H-Mg group). TOS total antioxidant status, $L P H$ lipid hydroperoxides, $M D A$ malondialdehyde, $L P S$ lipofuscin, $O S I$ oxidative stress index, $T A C$ total antioxidant capacity, $P S H$ protein sulfhydryl groups, $C E R$ ceruloplasmin, $S O D$ superoxide dismutase.

\begin{tabular}{|c|c|c|c|c|c|c|}
\hline & \multicolumn{2}{|c|}{ L-Mg group } & \multicolumn{2}{|c|}{$\mathrm{H}-\mathrm{Mg}$ group } & \multirow[t]{2}{*}{ Relative change $\%$} & \multirow[t]{2}{*}{$p$} \\
\hline & Mean & SD & Mean & SD & & \\
\hline TOS $(\mu \mathrm{mol} / 1)$ & 10.3 & 3.49 & 10.5 & 4.92 & $2 \%$ & 0.752 \\
\hline $\mathrm{LPH}(\mu \mathrm{mol} / \mathrm{l})$ & 2.91 & 1.72 & 3.17 & 2.20 & $9 \%$ & 0.311 \\
\hline MDA $(\mu \mathrm{mol} / \mathrm{l})$ & 3.08 & 1.37 & 2.72 & 1.13 & $-12 \%$ & 0.025 \\
\hline LPS (RU/l) & 583 & 101 & 564 & 120 & $-3 \%$ & 0.216 \\
\hline OSI (\%) & 0.99 & 0.76 & 0.93 & 0.53 & $-5 \%$ & 0.555 \\
\hline TAC (mmol/l) & 1.13 & 0.11 & 1.16 & 0.12 & $3 \%$ & 0.014 \\
\hline Bilirubin $(\mu \mathrm{mol} / \mathrm{l})$ & 10.7 & 3.89 & 13.6 & 6.50 & $27 \%$ & 0.009 \\
\hline $\mathrm{PSH}(\mu \mathrm{mol} / \mathrm{g}$ protein $)$ & 4.13 & 0.50 & 4.40 & 0.57 & $6 \%$ & $<0.001$ \\
\hline CER (mg/dl) & 43.5 & 6.82 & 42.2 & 5.98 & $-3 \%$ & 0.130 \\
\hline $\mathrm{SOD}(\mathrm{NU} / \mathrm{ml})$ & 20.6 & 3.99 & 19.9 & 3.54 & $-3 \%$ & 0.174 \\
\hline
\end{tabular}

$p$ value $-t$ test, $p<0.05$ 
Table 5 Oxidative stress markers in erythrocytes in low magnesium level group (L-Mg group) and high magnesium level group $(\mathrm{H}-$ Mg group). $M D A$

malondialdehyde, LPS lipofuscin, $G R$ glutathione reductase, GST glutathione S-transferase, GPX glutathione peroxidase, $C A T$ catalase, $S O D$ superoxide dismutase.

\begin{tabular}{|c|c|c|c|c|c|c|}
\hline & \multicolumn{2}{|c|}{ L-Mg group } & \multicolumn{2}{|c|}{$\mathrm{H}-\mathrm{Mg}$ group } & \multirow{2}{*}{$\begin{array}{l}\text { Relative } \\
\text { change \% }\end{array}$} & \multirow[t]{2}{*}{$p$} \\
\hline & mean & SD & mean & SD & & \\
\hline MDA (nmol/g Hb) & 220 & 62.60 & 229 & 78.07 & $4 \%$ & 0.350 \\
\hline LPS (RU/g Hb) & 659 & 207 & 638 & 233 & $-3 \%$ & 0.471 \\
\hline GR (IU/g Hb) & 6.84 & 1.51 & 7.15 & 1.41 & $5 \%$ & 0.101 \\
\hline GST (mIU/g Hb) & 190 & 75.4 & 175 & 72.13 & $-8 \%$ & 0.137 \\
\hline GPX (IU/g Hb) & 51.4 & 13.2 & 51.2 & 15.07 & $0 \%$ & 0.913 \\
\hline CAT (kIU/g Hb) & 451 & 57.3 & 463 & 68.22 & $3 \%$ & 0.135 \\
\hline $\mathrm{SOD}(\mathrm{NU} / \mathrm{mg} \mathrm{Hb})$ & 187 & 31.3 & 197 & 34.75 & $5 \%$ & 0.021 \\
\hline
\end{tabular}

$p$ value $-t$ test, $p<0.05$ magnesium metabolism as well as lead absorption, distribution, and excretion, such as type of exposure (environmental vs. occupational), duration of exposure, diet, levels of other elements, and many others.

There are many possible mechanisms of lead toxic action. Interferences between lead and hematopoiesis were investigated in animal and human studies. It has been established that lead downregulates activities of three enzymes involved in the heme biosynthesis pathway, $\delta$-aminolevulinic acid synthetase, $\delta$-aminolevulinic acid dehydratase, and ferrochelatase, in a dose-dependent manner. Consequently, lead poisoning results in anemia due to impaired hemoglobin synthesis. Ferrochelatase is a mitochondrial enzyme that catalyzes the insertion of iron into protoporphyrin. The inhibition of ferrochelatase results in the accumulation of protoporphyrin in erythrocytes. Zinc instead of iron binds to protoporphyin to form zinc protoporphyrin (ZPP) which serves as a marker of lead exposure [4]. In the present study, the levels of lead in the blood were not different between the examined groups; however, the level of ZPP was higher in the L-Mg group than in

Table 6 Correlations between magnesium level and selected parameters. $\mathrm{PbB}$ - blood lead level, $Z P P$ zinc protoporphyrin, $M D A$ malondialdehyde, $T A C$ total antioxidant capacity, $P S H$ protein sulfhydryl groups, $S O D$ superoxide dismutase, $P L T$ platelets.

\begin{tabular}{lll}
\hline $\begin{array}{l}\text { Correlations between magnesium } \\
\text { level and the levels of: }\end{array}$ & $R$ & $p$ \\
\hline $\mathrm{PbB}(\mu \mathrm{g} / \mathrm{dl})$ & -0.14 & 0.143 \\
$\mathrm{ZPP}(\mu \mathrm{g} / \mathrm{g} \mathrm{Hb})$ & -.26 & 0.005 \\
$\mathrm{MDA}(\mu \mathrm{mol} / \mathrm{l})$ & -0.16 & 0.017 \\
$\mathrm{TAC}(\mathrm{mmol} / \mathrm{l})$ & 0.13 & 0.048 \\
$\mathrm{PSH}(\mu \mathrm{mol} / \mathrm{g}$ protein $)$ & 0.21 & 0.001 \\
bilirubin $(\mu \mathrm{mol} / \mathrm{l})$ & 0.18 & 0.024 \\
SOD $(\mathrm{NU} / \mathrm{mg} \mathrm{Hb})$ & 0.13 & 0.048 \\
PLT $(\mathrm{G} / \mathrm{l})$ & -0.15 & 0.026 \\
\hline
\end{tabular}

$R$-values - Spearman's rank correlation, $p<0.05$ the $\mathrm{H}-\mathrm{Mg}$ group. Besides, there was a negative correlation between the levels of ZPP and magnesium. A negative association between ZPP level and magnesium level was also shown in the regression analysis. This observation suggests that low magnesium levels may enhance negative impact of lead on heme biosynthesis. On the other hand, this impact seems to be limited and not clinically significant since we simultaneously did not observe any differences between the examined groups in terms of the values of RBC count, HTC, and HBG level. Similarly, there was no difference between the values of the WBC counts in the examined groups.

By contrast to RBC and WBC counts, PLT count was higher in the L-Mg group compared with the H-Mg group. Additively, we observed a negative correlation between magnesium level and PLT count. Lead may interfere with the blood coagulation through many mechanisms, such as endothelial injury, reduced nitric oxide bioavailability, reduced tissue plasminogen activator level, and an increased production of plasminogen activator inhibitor-1. The associations between blood lead level and PLT count are controversial. Several animal studies have shown a positive association between chronic lead intoxication and PLT count, while several human studies have shown opposite results [26]. In our previous study, increased PLT count was reported in workers exposed to lead for a short period of time [27]. Nevertheless, chronic lead exposure did not result in altered PLT count in another group of workers [28]. Studies indicate also associations between serum magnesium level and platelet function; however, exact mechanisms remain unclear. It has been postulated that magnesium decreases platelet hyperactivity and adhesiveness. Reduced platelet aggregability releases them back to the bloodstream and increases PLT count. Besides, magnesium level has been linked with better bone marrow function, including megakaryocytopoiesis [29]. Consistently, Lu et al. [29] showed an inverse relation between serum magnesium level and thrombocytopenia in 8478 participants of The China Health and Nutrition Survey. Besides, Liu et al. [30] reported higher PLT count in patients without type 2 
Table 7 Regression analysis between magnesium level and selected parameters. $Z P P$ zinc protoporphyrin, $M D A$ malondialdehyde, $P S H$ protein sulfhydryl groups, $S O D$ superoxide dismutase.

\begin{tabular}{lllllrrr}
\hline & $R$ & $R^{2}$ & $R^{2}$-cor & $p$ & $-95 \% \mathrm{CI}$ & $+95 \% \mathrm{CI}$ & \multicolumn{1}{l}{$\beta$} \\
\hline ZPP $(\mu \mathrm{g} / \mathrm{g} \mathrm{Hb})$ & 0.19 & 0.036 & 0.030 & 0.012 & -6.31 & -0.79 & -0.19 \\
MDA $(\mu \mathrm{mol} / \mathrm{l})$ & 0.17 & 0.028 & 0.022 & 0.027 & -2.66 & -0.16 & -0.17 \\
PSH ( $\mu \mathrm{mol} / \mathrm{g}$ protein) & 0.22 & 0.051 & 0.045 & 0.003 & 0.29 & 1.35 & 0.22 \\
SOD (NU/mg Hb) & 0.17 & 0.028 & 0.022 & 0.027 & 4.50 & 74.38 & 0.17 \\
\hline
\end{tabular}

$p<0.05$ diabetes and central obesity with higher serum magnesium level than in those with lower serum magnesium level. Such observation was not confirmed in patients with diabetes and central obesity. In light of this information, lower PLT count in the L-Mg group than in the H-Mg group should be expected. Opposite results obtained in the present study may be due to possible additional mechanisms that are triggered by lead.

The ability of lead to induce oxidative stress is well-described. In our previous study, we have shown that chronic exposure to lead induces lipid peroxidation and oxidative DNA damage in a dose-dependent manner and modifies activities of antioxidant enzymes [31]. Magnesium deficiency is also believed to induce oxidative stress. There are several proposed mechanisms explaining negative effects of hypomagnesemia. One of them refers to antioxidant system. It has been reported that low serum magnesium level is accompanied with low glutathione level and decreased activity of antioxidant enzymes, such as superoxide dismutase, catalase, and glutathione peroxidase [7] [32]. Consistently, we reported higher serum MDA level in the L-Mg group compared with the $\mathrm{H}-\mathrm{Mg}$ group. Elevated level of lipid peroxidation marker may be related to simultaneously observed reduced serum level of sulfhydryl groups that is proportional to glutathione level, a major thiol antioxidant of the human body. Besides, reduced level of sulfhydryl groups should be interpreted as a main cause of reduced TAC level that was also observed. In erythrocytes, the levels of MDA did not differ between the examined groups; however, in the L-Mg group, we observed lower SOD activity than in the H-M group which confirms above-mentioned associations between magnesium and antioxidant enzymes. Differences between the examined groups in terms of the mentioned parameters related to oxidative stress and antioxidant defense are also supported by the regression analysis and correlations. These data confirm a hypothesis that low magnesium levels may enhance leadinduced oxidative stress and aggravate clinical manifestations of lead poisoning. Discussed above associations among lead, magnesium, and PLT count and function as well as mentioned disorders associated with hypomagnesemia, such as hypertension, atherosclerosis, cardiac arrhythmias, and infarct, led us to hypothesize that the coincidence of lead exposure and magnesium deficiency may be especially harmful to the cardiovascular system function.
Associations between lead and non-enzymatic antioxidants are less understood than those with antioxidant enzymes. In our previous studies on chronically and subchronically leadexposed workers, we reported a higher bilirubin level due to the exposure [27] [33]. Such results may be a result of the ability of lead to induce eryptosis [34] and the activity of the inducible form of heme oxygenase [35]. Besides, increased bilirubin level may be observed due to the lead hepatotoxicity. Damage to hepatocytes may impair bilirubin conjugation and block biliary tract leading to a release of unconjugated bilirubin into the bloodstream [36]. On the other hand, elevated serum bilirubin level is believed to be able to mitigate lead toxicity thanks to its antioxidant properties. An experimental study showed that bilirubin administration resulted in increased GSH level, enhanced the activity of antioxidant enzymes, and decreased the toxicity of $\delta$-aminolevulinic acid (ALA) in rats [37]. In light of this, lower bilirubin level in the L-Mg group than in the $\mathrm{H}-\mathrm{Mg}$ group should be regarded as not eligible. The associations between magnesium and bilirubin levels are not well-known. Sarici et al. [38] found a positive association between serum magnesium and bilirubin level in infants with hyperbilirubinemia and postulated magnesium efflux from cells to plasma as a result of the cellular injury related to bilirubin toxicity. In the present study, we also reported a positive correlation between magnesium and bilirubin levels; however, mechanisms underlying this observation need further investigation.

\section{Conclusions}

Low serum magnesium levels contribute to lead-induced oxidative stress, result in unfavorable modification of antioxidant system function, and promote lead-induced impairment of heme synthesis. Besides, serum magnesium level seems to be able to modify the associations between blood lead level and PLT count. Obtained results indicate that prevention of hypomagnesemia should be regarded as an important step in ensuring adequate prophylaxis of chronic lead poisoning.

Funding Information This work was supported by the Medical University of Silesia (KNW-2-08/N/8/N). 


\section{Compliance with Ethical Standards}

Study protocol was approved by the Bioethics Committee of Medical University of Silesia (Permission No. KNW/022/KB1/108/14).

Conflict of Interest The authors declare that they have no conflict of interest.

Informed Consent Informed consent was obtained from all individual participants included in the study.

Open Access This article is licensed under a Creative Commons Attribution 4.0 International License, which permits use, sharing, adaptation, distribution and reproduction in any medium or format, as long as you give appropriate credit to the original author(s) and the source, provide a link to the Creative Commons licence, and indicate if changes were made. The images or other third party material in this article are included in the article's Creative Commons licence, unless indicated otherwise in a credit line to the material. If material is not included in the article's Creative Commons licence and your intended use is not permitted by statutory regulation or exceeds the permitted use, you will need to obtain permission directly from the copyright holder. To view a copy of this licence, visit http://creativecommons.org/licenses/by/4.0/.

\section{References}

1. Luo T, Shen M, Zhou J, Wang X, Xia J, Fu Z, Jin Y (Apr. 2019) Chronic exposure to low doses of $\mathrm{Pb}$ induces hepatotoxicity at the physiological, biochemical, and transcriptomic levels of mice. Environ Toxicol 34(4):521-529

2. Bjørklund G, Crisponi G, Nurchi VM, Cappai R, Djordjevic AB, Aaseth J (2019) A review on coordination properties of thiolcontaining chelating agents towards mercury, cadmium, and lead, Molecules, 24, no. 18. MDPI AG

3. Kiełtucki J, Dobrakowski M, Pawlas N, Średniawa B, Boroń M, Kasperczyk S (2017) The analysis of QT interval and repolarization morphology of the heart in chronic exposure to lead. Hum Exp Toxicol 36(10):1081-1086

4. Assi MA, Hezmee MNM, Haron AW, Sabri MYM, Rajion MA (2016) The detrimental effects of lead on human and animal health. Vet World 9(6):660-671

5. E. Metryka et al. (2018) Lead (Pb) exposure enhances expression of factors associated with inflammation, International Journal of Molecular Sciences, 19, no. 6. MDPI AG

6. Kostov K, Halacheva L (2018) Role of magnesium deficiency in promoting atherosclerosis, endothelial dysfunction, and arterial stiffening as risk factors for hypertension, International Journal of Molecular Sciences, vol. 19, no. 6. MDPI AG

7. Morais JBS, Severo JS, Santos LR, de Sousa Melo SR, de Oliveira Santos R, de Oliveira ARS, Cruz KJC, do Nascimento Marreiro D (2017) Role of magnesium in oxidative stress in individuals with obesity. Biol Trace Elem Res 176(1):20-26

8. Gulson BL, Mizon KJ, Korsch MJ, Taylor AJ (2006) Low blood lead levels do not appear to be further reduced by dietary supplements. Environ Health Perspect 114(8):1186-1192

9. Erel O (2004) A novel automated direct measurement method for total antioxidant capacity using a new generation, more stable ABTS radical cation. Clin Biochem 37(4):277-285

10. Erel $\mathrm{O}$ (2005) A new automated colorimetric method for measuring total oxidant status. Clin Biochem 38(12):1103-1111
11. Arab K, Steghens JP (2004) Plasma lipid hydroperoxides measurement by an automated xylenol orange method. Anal Biochem 325(1):158-163

12. Ohkawa H, Ohishi N, Yagi K (1979) Assay for lipid peroxides in animal tissues by thiobarbituric acid reaction. Anal Biochem 95(2): 351-358

13. Tsuchida M, Miura T, Mizutani K, Aibara K (1985) Fluorescent substances in mouse and human sera as a parameter of in vivo lipid peroxidation. Biochim Biophys Acta 834(2):196-204

14. Koster JF, Biemond P, Swaak AJG (1986) Intracellular and extracellular sulphydryl levels in rheumatoid arthritis. Ann Rheum Dis 45(1):44-46

15. Richterich R (1971) Chemia kliniczna: teoria i praktyka

16. Oyanagui Y (1984) Reevaluation of assay methods and establishment of kit for superoxide dismutase activity. Anal Biochem 142(2):290-296

17. Johansson LH, Håkan Borg LA (1988) A spectrophotometric method for determination of catalase activity in small tissue samples. Anal Biochem 174(1):331-336

18. Habig WH, Jakoby WB (1981) Assays for differentiation of glutathione S-transferases. Methods Enzymol 77(C):398-405

19. Paglia DE, Valentine WN (1967) Studies on the quantitative and qualitative characterization of erythrocyte glutathione peroxidase. J Lab Clin Med 70(1):158-169

20. Li Y, Li M, Lv Q, Chen G, Chen J, Li S, Mo Y, Ou S, Yuan Z, Lu G, Jiang Y (2015) Relationship of lead and essential elements in whole blood from school-age children in Nanning, China. J Trace Elem Med Biol 32:107-111

21. Wu Y, Yang X, Ge J, Zhang J (2011) Blood lead level and its relationship to certain essential elements in the children aged 0 to 14 years from Beijing, China. Sci Total Environ 409(16):30163020

22. Liu KS, Mao XD, Shi J, Dai CF, Gu P (2015) Towards bio monitoring of toxic (lead) and essential elements in whole blood from 1to72-month old children: a cross-sectional study. Afr Health Sci 15(2):634-640

23. Zhao TT, Chen B, Wang HP, Wang R, Zhang H (2013) Evaluation of toxic and essential elements in whole blood from 0- to 6-year-old children from Jinan, China. Clin Biochem 46(7-8):612-616

24. Długaszek M, Skrzeczanowski W (2017) Relationships between element contents in Polish children's and adolescents' hair. Biol Trace Elem Res 180(1):6-14

25. Kosik-Bogacka DI, Lanocha-Arendarczyk N, Kot K, Zietek P, Karaczun M, Prokopowicz A, Kupnicka P, Ciosek Z (2018) Calcium, magnesium, zinc and lead concentrations in the structures forming knee joint in patients with osteoarthritis. J Trace Elem Med Biol 50:409-414

26. Barman T, Kalahasthi R, Rajmohan HR (2014) Effects of lead exposure on the status of platelet indices in workers involved in a lead-acid battery manufacturing plant. J Expo Sci Environ Epidemiol 24(6):629-633

27. Dobrakowski M, Kasperczyk A, Pawlas N, Birkner E, Hudziec E, Chwalińska E, Kasperczyk S (2016) Association between subchronic and chronic lead exposure and levels of antioxidants and chemokines. Int Arch Occup Environ Health 89(7):1077-1085

28. Chwalba A, Maksym B, Dobrakowski M, Kasperczyk S, Pawlas N, Birkner E, Kasperczyk A (2018) The effect of occupational chronic lead exposure on the complete blood count and the levels of selected hematopoietic cytokines. Toxicol Appl Pharmacol 355:174-179

29. Lu L, Zhan Y, Yu J, Sui L (2016) Prevalence of thrombocytopenia and its association with serum magnesium. Biol Trace Elem Res 169(1):46-51

30. Liu D, Yu L, Li S, Zhang Q, Zhu L, Liu Q, Lin H, Zhang J (2019) Association between serum magnesium and blood count: influence of type 2 diabetes and central obesity. Br J Nutr 121(11):1287-1293 
31. Dobrakowski $\mathrm{M}$ et al. (2017) Oxidative DNA damage and oxidative stress in lead-exposed workers, Hum. Exp. Toxicol., vol. 36, no. 7

32. Zheltova AA, Kharitonova MV, Iezhitsa IN, Spasov AA (2016) Magnesium deficiency and oxidative stress: an update, BioMedicine (Netherlands), vol. 6, no. 4. China Medical University, pp. 8-14

33. Dobrakowski M, Zalejska-Fiolka J, Wielkoszyński T, Świętochowska E, Kasperczyk S (2014) Wpływ przewlekłego zatrucia ołowiem na nieenzymatyczny układ antyoksydacyjny. Med Pr 65(4):443-451

34. Aguilar-Dorado IC, Hernández G, Quintanar-Escorza MA, Maldonado-Vega M, Rosas-Flores M, Calderón-Salinas JV (2014) Eryptosis in lead-exposed workers. Toxicol Appl Pharmacol 281(2):195-202

35. Vargas H, Castillo C, Posadas F, Escalante B (2003) Acute lead exposure induces renal haeme oxygenase- 1 and decreases urinary $\mathrm{Na}+$ excretion. Hum. Exp. Toxicol. 22(5):237-244
36. Soussi A, Gargouri M, El Feki A (2018) Potential immunomodulatory and antioxidant effects of walnut Juglans regia vegetable oil against lead-mediated hepatic damage and their interaction with lipase activity in rats. Environ Toxicol 33(12):1261-1271

37. Noriega GO, Tomaro ML, Del Batlle AMC (2003) Bilirubin is highly effective in preventing in vivo $\delta$-aminolevulinic acid-induced oxidative cell damage. Biochim Biophys Acta - Mol Basis Dis 1638(2):173-178

38. Sarici SU, Serdar MA, Erdem G, Alpay F (2004) Evaluation of plasma ionized magnesium levels in neonatal hyperbilirubinemia. Pediatr Res 55(2):243-247

Publisher's Note Springer Nature remains neutral with regard to jurisdictional claims in published maps and institutional affiliations. 